\title{
Human Lactation II: Endogenous Fatty Acid Synthesis by the Mammary Gland ${ }^{1}$
}

\author{
DAVID L. HACHEY, GARY H. SILBER, WILLIAM W. WONG, AND CUTBERTO GARZA \\ USDA/ARS Children's Nutrition Research Center, Department of Pediatrics, Baylor College of Medicine and \\ Texas Children's Hospital, Houston, Texas 77030
}

\begin{abstract}
We studied the effects of a diet that was low in fat, high in carbohydrate (CHO) on milk lipid composition and de novo endogenous fatty acid synthesis by the mammary gland in five lactating women. The women consumed either a low fat (LF) $(5 \%$ fat, $80 \%$ CHO) diet or a high fat (HF) (40\% fat, $45 \% \mathrm{CHO})$ diet. Fat synthesis was determined after an oral dose of $500 \mathrm{mg} / \mathrm{kg} \mathrm{D}_{2} \mathrm{O}$ by measuring the incorporation of deuterium into $\mathrm{C10:0}$ to $\mathrm{C18:0}$ saturated fatty acids of milk fat and plasma triglycerides by gas chromatography-mass spectrometry. Synthesis of plasma C16:0 and C18:0 triglycerides was barely detectable while women consumed the HF diet, but was increased 6-fold during the LF diet. Medium chain fatty acids secreted by the mammary gland increased from $12.8 \%$ (HF diet) to $16.3 \%$ (LF diet) in milk fat from four of five subjects $(p=0.027)$. Medium chain fatty acid secretion, however, increased from $13.9 \%$ (HF diet) to $29.9 \%$ (LF diet) in one subject. The primary fatty acids synthesized during lactation were $C 10: 0, C 12: 0$, and $C 14: 0$ in the majority of women studied. The LF diet significantly increased the apparent synthesis of C14:0 $(p=0.05)$, whereas no changes were observed in $\mathrm{C12:0}, \mathrm{C16:0}$, or C18:0. One subject had highly enriched C16:0 and C18:0 fatty acids in her milk on the LF diet, which could have been the result of mammary synthesis or of transport and secretion of hepatically synthesized lipids. (Pediatr Res 25:63-68, 1989)
\end{abstract}

\section{Abbreviations}

CHO, carbohydrate

LF, low fat

HF, high fat

FA, fatty acids

FAME, fatty acid methyl esters

GC-MS, gas chromatography-mass spectrometry

ApoB, apolipoprotein B

TG, triglycerides

MCT, medium chain triglycerides $(\mathrm{C10}, \mathrm{C12}, \mathrm{C14})$

CM, chylomicrons

VLDL, very low density lipoproteins

Received February 22, 1988; accepted September 7, 1988.

Correspondence and reprint requests to David L. Hachey, Ph.D., Children's Nutrition Research Center, 1100 Bates, Houston, TX 77030.

'Publication of the USDA/ARS Children's Nutrition Research Center, Department of Pediatrics, Baylor College of Medicine, and Texas Children's Hospital, Houston, TX.

Supported in part with federal funds from the U.S. Department of Agriculture, Agricultural Research Service under Cooperative Agreement 58-7MN1-6-100. The contents of this publication do not necessarily reflect the views or policies of the U.S. Department of Agriculture, nor does the mention of trade names, commercial products, or organizations imply endorsement by the U.S. Government.
Milk lipid is comprised of $98 \%$ TG, $1 \%$ phospholipid, and $0.5 \%$ cholesterol and cholesterol ester, and provides 50 to $60 \%$ of an infant's energy intake (1). Milk TG contain FA derived from three sources: de novo mammary synthesis, dietary lipids, and mobilized adipose or hepatic lipids (2). Variations in the FA intake and composition of the mother's diet are known to alter the FA composition of her milk (3); for example, a LF, high $\mathrm{CHO}$ diet increased proportions of $\mathrm{C10:0,} \mathrm{C12:0}$, and $\mathrm{C14}: 0 \mathrm{FA}$ whereas the proportion of $\mathrm{C} 16$ and $\mathrm{C} 18 \mathrm{FA}$ was reduced (4-6). This diet, however, did not change total milk fat content significantly, and these studies were unable to distinguish between altered mammary synthesis, changes in whole body lipogenesis, and lipid transport induced by the high $\mathrm{CHO}$ diet.

The incorporation of deuterium into cholesterol and FA during lipogenesis was first demonstrated in the classic work of Rittenberg and Schoenheimer (7), and 22 of 31 protons in palmitic acid are known to be derived from body water (8). Despite the widespread use of deuterium to measure total body water (9), it has not been applied to the systematic study of lipogenesis in humans.

Isotopic tracers are required to distinguish between FA synthesized de novo by the body and those of dietary origin. We have described the use of specifically labeled FA to measure the transport of dietary fat across the lactating mammary gland (10). The low level of lipogenesis in most tissues, however, and the dilution of newly synthesized lipid into a large endogenous pool require sensitive, high precision analytical techniques for measurements of small changes in isotopic enrichment above the natural abundance.

We have developed methods to measure the incorporation of deuterium from body water into specific milk FA. These methods were used to study the effect of $\mathrm{HF}$, high $\mathrm{CHO}$ diets on de novo mammary lipid synthesis and the attendant changes in milk lipid composition.

\section{MATERIALS AND METHODS}

Deuterium oxide ( 99.8 atom \% D) was purchased from MSD Isotopes (Montreal, Canada). The ${ }^{2} \mathrm{H}_{2} \mathrm{O}$ was administered orally without further purification. HPLC quality solvents and derivatization reagents were purchased from Fisher Chemical Co. (Houston, TX) and from Aldrich Chemical Co. (Milwaukee, WI). Lipid internal standards were obtained from Sigma Chemical Co. (St. Louis, MO).

Study design. Five women were studied using a two-part crossover design in which each subject served as her own control. Written informed consent was obtained from each volunteer. The experimental protocol was approved by the Baylor College of Medicine Institutional Review Board for Human Research and by the Texas Children's Hospital Committee on Investigations and Publications. All subjects were normal, healthy, nonsmoking women, 28 to $36 \mathrm{y}$ old, whose pregnancies and deliveries 
had been normal. They were studied at 3 mo postpartum, except for subject 3 who was studied at $1.7 \mathrm{mo}$. Subjects were asked to keep a 24-h diet record before each of the two phases of the study. This record was used to determine their average daily caloric intake.

Subjects consumed a controlled, LF diet ( $5 \%$ fat, $15 \%$ protein, and $80 \% \mathrm{CHO}$ ) for 5 days; 1 mo later, they consumed a controlled, HF diet ( $40 \%$ fat, $15 \%$ protein, and $45 \% \mathrm{CHO}$ ) for 5 days. The energy content of these diets was adjusted to match the prestudy energy intake of each woman. The subjects consumed their usual diets between the two phases of the study and were provided with all foods consumed during the controlled diet periods. Subjects were admitted to the Clinical Research Center at Texas Children's Hospital on the evening of the 4th day of the controlled diet. On the morning of the 5 th day, each subject was given an oral dose of ${ }^{2} \mathrm{H}_{2} \mathrm{O}(250$ or $500 \mathrm{mg} / \mathrm{kg})$. Milk was collected from alternate breasts at $0,3,6,9,12,15$, and 24 $\mathrm{h}$ using an Egnell Cam I electric breast pump (Egnell, Inc., Cary, IL) and was flash-frozen for subsequent analysis. Blood $(5 \mathrm{ml})$ was collected by venipuncture at 0,8 , and $24 \mathrm{~h}$, and the plasma was collected by centrifugation and was frozen. Subjects were released on the morning of the 6th day after the 24 -h postdose milk and blood collections.

Plasma lipid analysis. Plasma cholesterol, TG, and apolipoprotein B were measured by the Atherosclerosis Laboratory at The Methodist Hospital, Houston, TX. Total plasma cholesterol and TG were measured using a COBAS-BIO analyzer (Roche Diagnostics, Montclair, NJ) using the respective enzymatic kits (Boehringer Mannheim Diagnostics, Indianapolis, IN). Total ApoB was quantitated by RIA (10).

Isolation and sample derivatization. Total milk lipids were extracted using chloroform:methanol $(2: 1)$ and were converted to FAME using methods described previously (11). An internal standard mixture that contained heptadecanoic acid $(10 \mu \mathrm{g})$, triheptadecanoin $(100 \mu \mathrm{g})$, cholesteryl heptadecanoate $(100 \mu \mathrm{g})$, and di-heptadecanoyl-L- $\alpha$-phosphatidylcholine $(100 \mu \mathrm{g})$ was added to plasma before extraction with chloroform:methanol $(2: 1)$. The plasma lipids were separated into free FA, TG, cholesterol esters, and total phospholipids using an aminopropyl solid phase extraction cartridge before transesterification (11).

Gas chromatography. FAME were analyzed using a $30-\mathrm{m} \times$ $0.25-\mathrm{mm}, 0.20-\mu \mathrm{m}$ SP-2330 capillary column (Supelco Inc., Bellefonte, PA). Chromatographic temperatures and conditions were: injector $230^{\circ} \mathrm{C}$, detector $230^{\circ} \mathrm{C}$, and column oven program 140 to $225^{\circ} \mathrm{C}$ at $5^{\circ} \mathrm{C} / \mathrm{min}$. Quantitation was based on the amount of $\mathrm{C} 17: 0$ internal standard added to plasma.

Isotope-ratio mass spectrometry. Deuterium enrichment in milk water was quantitated by gas-isotope-ratio mass spectrometry. From each defatted milk sample, $10 \mu \mathrm{l}$ were reduced to hydrogen gas over zinc shot at $450^{\circ} \mathrm{C}$, according to the method of Wong et al. (12), and analyzed using a Finnigan MAT Delta E mass spectrometer (Finnigan MAT, San Jose, CA). Body water enrichment data were used to calculate total body water, and, subsequently, to derive the percentage of body fat in these subjects using the equation:

$$
\text { Body fat }(\%)=100\left[1-\frac{(\text { Total body water }) / 0.72}{\text { Body weight }}\right]
$$

$G C-M S$. The isotopic abundance of $\mathrm{C} 10: 0, \mathrm{C} 12: 0, \mathrm{C} 14: 0$, C16:0, and C18:0 FAME was measured using a Hewlett-Packard 5988A GC-MS system (Hewlett-Packard Co., Palo Alto, CA). Samples were chromatographed using a $30-\mathrm{m} \times 0.32-\mathrm{mm}, 0.25-$ $\mu \mathrm{m}$ DB-225 capillary column (J \& W Scientific Inc., Folsom, $\mathrm{CA}$ ). Chromatographic temperature conditions were: injector, $250^{\circ} \mathrm{C}$, GC-MS interface, $200^{\circ} \mathrm{C}$, column oven program $100-$ $250^{\circ} \mathrm{C}$ at $10^{\circ} \mathrm{C} / \mathrm{min}$. GC-MS conditions were: $70 \mathrm{eV}$ electron ionization, ion source temperature $200^{\circ} \mathrm{C}$, electron multiplier 2000 to $2400 \mathrm{~V}$. Deuterium isotopic abundances were measured by selected ion recording using the molecular ion of each FAME.
Specific ratios were quantitated for $\mathrm{C} 10: 0(\mathrm{~m} / \mathrm{z} 187 / 186$ and 188/186), C12:0 (m/z 215/214 and 216/214), C14:0 (m/z 243/ 242 and $244 / 242), \mathrm{C} 16: 0(\mathrm{~m} / \mathrm{z} 271 / 270$ and 272/270), and C18:0 (m/z 299/298 and 300/298). Five replicate sets of isotope ratio measurements were performed on each sample for statistical purposes. Isotopic enrichment in each FA was calculated by subtracting the isotope ratio measured at time zero from that measured for each subsequent sample.

Computation of deuterium enrichment of $F A$. The intensities of satellite ions in the mass spectra of FA reflect their natural isotopic enrichments in ${ }^{2} \mathrm{H},{ }^{13} \mathrm{C},{ }^{17} \mathrm{O}$, and ${ }^{18} \mathrm{O}$ and can be predicted from their molecular composition (13). Calculation of the isotopic enrichment of deuterium in organic FA from changes in these intensities requires knowledge of the deuterium enrichment of body water, the numbers of hydrogen atoms in the FA that are derived from body water, and the contribution (if any) of deuterium isotope effects. A program to compute the maximum anticipated enrichment for each FA from the observed enrichment of total body water was written in Pascal for the IBM personal computer. This program assumes 1) that any isotope effects have equal consequences on all FA, 2) that body waterderived hydrogens on all FA are equivalent, and 3) that there are two populations of hydrogen atoms within the FA molecule. One population is derived from carbon-bound precursors and has a constant enrichment at natural abundance levels; the second is derived from water; its enrichment reflects total body water enrichment. The program calculates the cumulative probability that the $M+1$ ion will contain at least 1 deuterium atom and that the $M+2$ ion will have at least 2 deuterium atoms. Using the deuterium enrichment of water measured in milk at 3 $\mathrm{h}$, it was thus possible to calculate the maximum theoretical increase in the ratio of ion intensities of $M+1 / M$ and $M+2 /$ $M$ for each saturated FA from C10:0 to C18:0. The relationship between body water deuterium enrichment and the enrichment calculated for palmitate is shown in Figure 1. These values showed that the GC-MS analytical precision would be sufficient to measure $0.1 \mathrm{~mol} \%$ excess (MPE) deuterated FAME for measurements using the $M+1$ ion and 0.03 MPE for measurements using the $\mathrm{M}+2$ ion. All FA enrichment data were normalized to the maximum value for that FA given the total body water enrichment of that subject, and the data were expressed as a percentage. This calculation permitted a direct comparison between the shorter chain FA and the longer chain FA that circumvented the absolute differences in numbers of body water-derived hydrogens reflected in the raw ion intensity ratios.

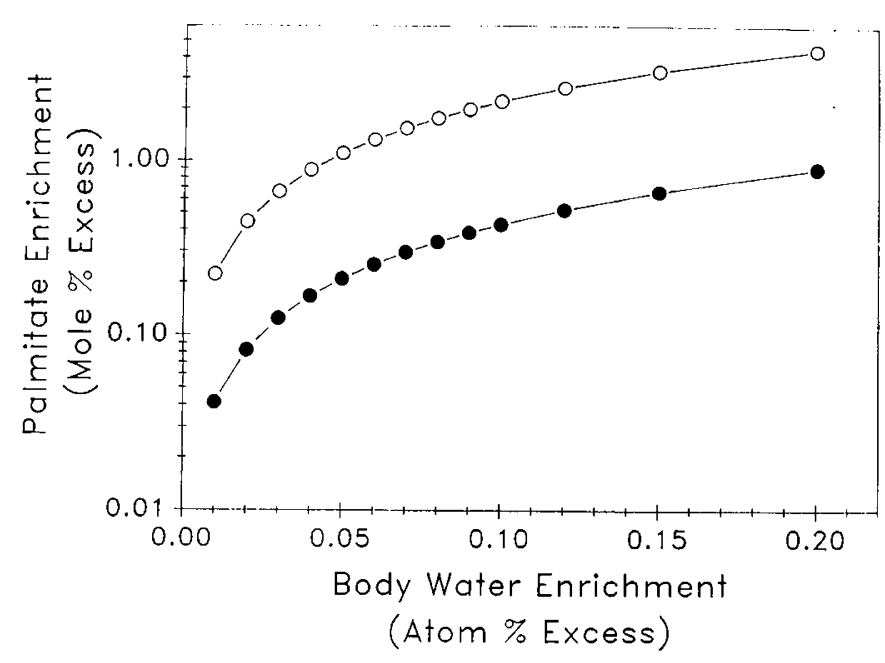

Fig. 1. Theoretical incorporation of deuterium into the $M+1$ ion $(O)$ and the $M+2$ ion $(\mathbf{O})$ of palmitic acid versus the deuterium enrichment in body water. 


\section{RESULTS}

Dietary effects on milk fat composition. Table 1 summarizes the subjects' clinical data and their diet analyses. Figure 2 illustrates the relative composition of milk lipid FA on the LF and $\mathrm{HF}$ diets. The data in Figure $2 A$ are the mean FA compositions of eight individual milk samples collected from subjects $1,2,4$, and 5 during the 5th day of the study. MCT increased from 12.8 $\pm 2.3 \%$ (HF diet) to $16.3 \pm 1.8 \%$ (LF diet) in these four subjects $(p=0.027)$. We observed a rise in the percentage of $16: 1(p=$ $0.05)$ and in 20:4 $(p=0.1)$ on the LF diet and a decrease in C18:0 $(p=0.01)$ and $C 18: 3(p=0.1)$. Figure $2 B$ shows the mean FA composition of milk samples collected from subject 3 who had the most exaggerated response to the LF diet. Her milk FA composition was similar to that of the other subjects during the HF diet period.

Plasma lipid measurements. Table 2 summarizes the mean fasting plasma levels of cholesterol, TG, and $A p o B$ that were obtained from the 0 - and 24-h samples under both dietary conditions. Statistically significant differences, based on a paired $t$ test, were observed between dietary periods for all plasma lipids. Figure $3 A$ and $B$ show the magnitude of the postprandial rise in plasma TG during the LF and HF diet periods, respectively. The maximum rise occurred $4 \mathrm{~h}$ after the noon meal, which should be near the maximum postprandial plasma TG levels, based on our earlier work (11) and $8 \mathrm{~h}$ after the subjects consumed the ${ }^{2} \mathrm{H}_{2} \mathrm{O}$.

Total body water measurements. Table 3 summarizes the body water ${ }^{2} \mathrm{H}$ enrichment, the percentage of body fat, the milk fat concentration, milk volume, and MCT production. The wide range in MCT production is explained by differences in the volume of milk secreted by individual subjects. Body water enrichment data were used to calculate the maximum enrichment in specific FA to be expected if two thirds of the organic hydrogen were derived from body water. A change in the percentage of body fat and body weight $(>1 \mathrm{~kg})$ was observed in subject 1 between the two diet periods. The body fat and body weight of the other subjects remained constant during both diet periods. We observed a significant positive correlation $(r=0.79)$ between the percentage of body fat and the percentage of milk fat during the LF diet period. This relationship was not as strong $(r=0.51)$ during the HF diet.

Milk fatty acid synthesis. The incorporation of deuterium into $\mathrm{C} 12: 0, \mathrm{C14}: 0, \mathrm{C16}: 0$, and C18:0 FA is shown in Figure 4 for women who displayed the "typical" diet response. The data for C10:0 FA were obtained in these subjects, but the low amounts of C10:0 FA present in human milk prevented precise measurement of isotopic enrichment in most cases. The isotopic enrichment pattern in C10:0 FA was similar to the C12:0 FA enrichment in two subjects where the analytical precision permitted such comparisons. A statistically significant difference in the relative enrichment of $\mathrm{C14:0}(p=0.05)$ was observed at $24 \mathrm{~h}$; no significant differences were observed in $\mathrm{C} 12: 0, \mathrm{C16}: 0$, or $\mathrm{C} 18: 0$. Figure 5 shows the isotopic enrichment pattern in subject 3 , who displayed the greatest response to the HF, high $\mathrm{CHO}$ diet. Plasma lipid synthesis. The isotopic enrichment observed in plasma TG is shown in Figure 6. The data are expressed as the relative isotopic enrichment above the baseline measurement at time 0 , normalized to the theoretical ${ }^{2} \mathrm{H}$ enrichment calculated for $\mathrm{C} 16: 0$ and $\mathrm{C} 18: 0$ based on body water ${ }^{2} \mathrm{H}$ enrichment. Only the data for $\mathrm{C} 16: 0$ and $\mathrm{C} 18: 0 \mathrm{FA}$ are shown. Virtually no $\mathrm{C10}: 0$ and C12:0 FA were detected in plasma lipids, and the amount of $\mathrm{C14:0}$ was usually too low to permit accurate isotopic enrichment measurements. Figure $6 \mathrm{~A}$ shows the incorporation of ${ }^{2} \mathrm{H}$ from body water into plasma TG in subjects 4 and 5 , both of whom responded similarly to the LF, high CHO diet. Similarly, Figure $6 B$ shows the incorporation of ${ }^{2} \mathrm{H}$ into plasma TG of subject 3 , whose response to the LF diet was greater than that of the other subjects.

\section{DISCUSSION}

Our investigation of the effects of two levels of lipid intake on milk FA synthesis in five lactating women showed that their milk fat contained more MCT when they consumed the LF diet compared with the HF diet. Slightly more energy $(1.6 \mathrm{kcal} / \mathrm{kg})$ was consumed during the HF diet, but the difference was not statistically significant. Total milk volumes secreted during the LF diet period were slightly greater than those during the $\mathrm{HF}$ diet, although milk fat concentration was decreased. The greater volumes of milk secreted, however, were insufficient to maintain total fat secretion at levels observed during the HF diet period. Whereas we had expected the LF diet to induce greater changes in milk lipid composition, additional changes were not observed beyond the 3rd day of the LF diet. Klein et al. (14) have described rapid adjustments in the ${ }^{13} \mathrm{C}$ isotopic composition of the major components in bovine milk that were due to changes in the isotopic composition of the bovine diet.

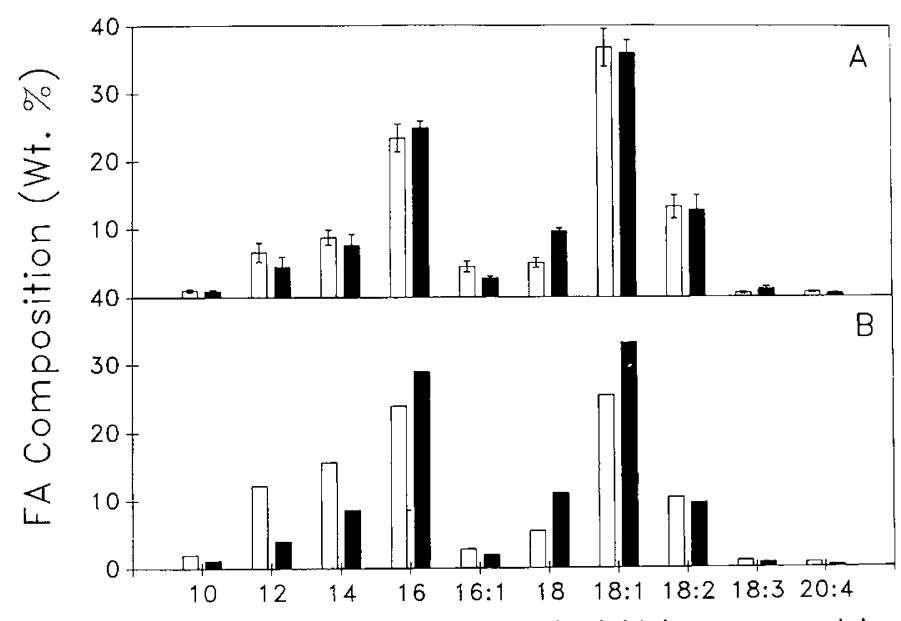

Fig. 2. The FA composition of human milk lipids in women receiving either a LF, high CHO diet $(\square)$ or a HF diet $(\square)$. $A$, typical mean lipid composition from four women who responded similarly. $B$, lipid composition from an individual who had an anomalous response.

Table 1. Individual subject characteristics

\begin{tabular}{|c|c|c|c|c|c|c|c|c|c|c|}
\hline \multirow[b]{2}{*}{ Subject } & \multirow[b]{2}{*}{$\mathrm{Ht}(\mathrm{cm})$} & \multirow[b]{2}{*}{ Wt (kg) } & \multirow[b]{2}{*}{ Age (y) } & \multirow{2}{*}{$\begin{array}{l}\text { Postpartum age } \\
\text { (mo) }\end{array}$} & \multicolumn{3}{|c|}{ LF nutrient intakes } & \multicolumn{3}{|c|}{ HF nutrient intakes } \\
\hline & & & & & $(\mathrm{kcal} / \mathrm{kg})$ & $(\%$ fat $)$ & $(\% \mathrm{CHO})$ & $(\mathrm{kcal} / \mathrm{kg})$ & $(\%$ fat $)$ & $(\% \mathrm{CHO})$ \\
\hline 1 & 167.6 & 70.3 & 34.8 & 2.9 & 34.9 & 5.0 & 79.4 & 36.8 & 46.1 & 40.3 \\
\hline 2 & 158.8 & 58.5 & 32.6 & 3.0 & 40.5 & 5.2 & 78.6 & 45.9 & 46.4 & 40.1 \\
\hline 3 & 154.9 & 56.7 & 30.3 & 1.7 & 45.9 & 5.7 & 79.0 & 45.2 & 47.2 & 39.4 \\
\hline 4 & 154.9 & 55.3 & 35.9 & 3.8 & 45.4 & 4.6 & 79.8 & 43.8 & 39.6 & 46.7 \\
\hline 5 & 165.1 & 89.4 & 27.9 & 3.3 & 26.9 & 5.3 & 78.5 & 29.6 & 45.5 & 41.3 \\
\hline Mean & 160.3 & 66.0 & 32.3 & 2.9 & 38.7 & 5.2 & 79.1 & 40.3 & 45.0 & 41.6 \\
\hline $\mathrm{SD}$ & 5.9 & 14.3 & 3.3 & 0.8 & 8.0 & 0.4 & 0.5 & 7.0 & 3.1 & 3.0 \\
\hline CV (\%) & 3.7 & 21.7 & 10.1 & 25.8 & 20.6 & 7.5 & 0.7 & 17.3 & 6.8 & 7.1 \\
\hline
\end{tabular}


Subject 3 demonstrated the greatest response to the LF diet; her medium chain fat increased from 13.9 to $29.9 \%$ of the milk lipids, and her milk fat decreased from 2.1 to $1.1 \%$. Two conditions have been associated with an increased MCT content of human milk, but only one with both an increased MCT content and a significant decline in total fat content. Type I hyperlipoproteinemia has been reported to increase MCT and to decrease total fat secretion by restricting the lipolysis and transport of plasma TG across the mammary gland, because of the inherited absence of lipoprotein lipase (15). Nothing in the clinical history of this subject, e.g. diabetes or type I hyperlipoproteinemia,

Table 2. Plasma lipid concentrations determined in fasting subjects

\begin{tabular}{|c|c|c|c|c|c|c|c|c|}
\hline \multirow[b]{2}{*}{ Subject } & \multicolumn{2}{|c|}{ Cholesterol } & \multicolumn{2}{|c|}{ Triglycerides } & \multicolumn{2}{|c|}{ ApoB } & \multicolumn{2}{|c|}{ TG/ApoB } \\
\hline & LF & $\mathrm{HF}$ & LF & $\mathrm{HF}$ & LF & $\mathrm{HF}$ & LF & $\mathrm{HF}$ \\
\hline 1 & 254 & 279 & 182 & 114 & 101 & 113 & 1.80 & 1.01 \\
\hline 2 & 160 & 177 & 68 & 54 & 49 & 58 & 1.39 & 0.94 \\
\hline 3 & 146 & 220 & 72 & 58 & 67 & 71 & 1.07 & 0.82 \\
\hline 4 & 198 & 289 & 161 & 70 & 72 & 113 & 2.24 & 0.62 \\
\hline 5 & 160 & 174 & 149 & 95 & 59 & 63 & 2.54 & 1.51 \\
\hline Mean & 184 & 228 & 126 & 78 & 70 & 84 & 1.81 & 0.98 \\
\hline $\mathrm{SD}$ & 44 & 55 & 53 & 26 & 20 & 27 & 0.60 & 0.33 \\
\hline$p^{*}$ & 0.025 & & 0.017 & & 0.057 & & 0.013 & \\
\hline
\end{tabular}

* Probability, paired $t$, of finding a significant difference in each category of plasma lipid among individuals consuming the LF and HF diets.

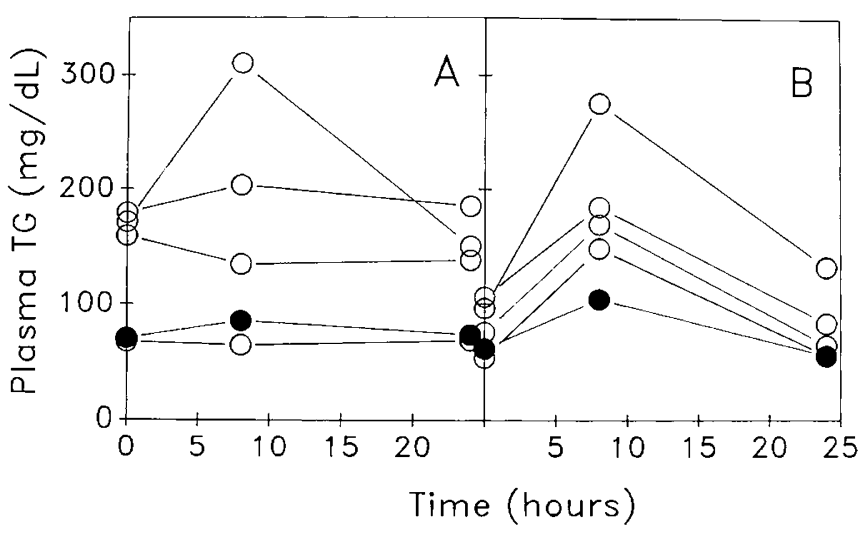

Fig. 3. The postprandial rise in plasma TG during a LF diet $(A)$ and during a HF diet $(B)$. Subject $3(\bullet)$. Subjects $1,2,4$, and $5(O)$. suggested an explanation for her response to the LF diet. Consumption of a high $\mathrm{CHO}$ diet at levels $50 \%$ above energy requirements has been associated with increased MCT concentration, but no change in total fat $(4,6)$. Although this subject had the lowest percentage of body fat of the group, her energy intakes, when normalized to body weight, were among the highest in the study, and she was one of two subjects whose percentage of body fat increased during the month that separated both diet periods. The increased MCT content of this woman's milk may have resulted from the effects of insulin, which would have been elevated by the high $\mathrm{CHO}$, hypercaloric diet. Insulin stimulates glucose transport across cell membranes, thus providing greater availability of glucose for lipid synthesis, which is stimulated by insulin as well. At the same time, elevated insulin levels will suppress lipolysis of adipose tissue lipids, thus restricting the supply of a major source of milk lipids. Her response to the HF diet was identical to that of the other women.

Subject 3 differed from the other subjects in an additionally important aspect; highly enriched $\mathrm{C} 16: 0$ and $\mathrm{C} 18: 0$ were found in her milk when she consumed the LF diet. The highly enriched $\mathrm{C} 16: 0$ and $\mathrm{C} 18: 0$ found in this subject's milk probably originated as TG-rich VLDL lipids that were synthesized by the liver in response to the high $\mathrm{CHO}$ meal and were subsequently converted into milk TG. The isotopic enrichment of these lipids was not diluted significantly by dietary or adipose $\mathrm{TG}$, as shown by the high enrichments measured in the plasma TG.

Plasma lipid levels were determined in these women on both the HF and LF diets; the results from our subjects on the HF diet were nearly identical to those reported by Knopp et al. (16) for lactating women on uncontrolled diets. Individual subjects invariably had lower cholesterol and ApoB levels and had higher TG levels on the LF diet. One significant change attributable to diet was the increased TG to ApoB ratio $(p=0.013)$, which was expected when subjects consumed a fat-restricted diet (17). This observation may be explained by increased hepatic synthesis and secretion of large, TG-rich VLDL particles by subjects on the LF diet.

In our studies, $\mathrm{C} 12: 0$ had the highest incorporation of deuterium into FA that were newly synthesized by the mammary gland. On the basis of approximately identical curves (Fig. 4) for the LF diet and the HF diet, all of the C12:0 found in milk was provided by de novo synthesis and was not diluted by unlabeled dietary lipids. These results are probably valid as well for $\mathrm{C} 10: 0$; we have reliable data from two subjects to support this conclusion. In contrast, more $\mathrm{C} 14: 0$ was synthesized by the mammary gland of women when they consumed the LF diet rather than the HF diet, as shown by the difference in isotopic enrichment in C14:0 between the two diets. These data indicate that approximately $45 \%$ of the C14:0 obtained from mothers on the HF diet

Table 3. Isotopic enrichment in body water, percentage of body fat, percentage of milk fat, and MCT production during the LF and HF diets

\begin{tabular}{|c|c|c|c|c|c|c|c|c|c|c|}
\hline \multirow[b]{2}{*}{ Subject } & \multicolumn{2}{|c|}{$\begin{array}{c}{ }^{2} \mathrm{H}_{2} \mathrm{O} \text { enrichment } \\
\text { (APE) }\end{array}$} & \multicolumn{2}{|c|}{ Body fat (\%) } & \multicolumn{2}{|c|}{ Milk fat (\%) } & \multicolumn{2}{|c|}{$\begin{array}{c}\mathrm{MCT}(\mathrm{g} / \text { day/ } \\
\text { breast) }\end{array}$} & \multicolumn{2}{|c|}{$\begin{array}{l}\text { Milk vol (g/day/ } \\
\text { breast) }\end{array}$} \\
\hline & LF & $\mathrm{HF}$ & LF & $\mathrm{HF}$ & LF & $\mathrm{HF}$ & $\mathrm{LF}$ & $\mathrm{HF}$ & $\mathrm{LF}$ & $\mathrm{HF}$ \\
\hline $1^{*}$ & 0.0447 & 0.0379 & 28.0 & 16.0 & 3.4 & 3.5 & 1.4 & 1.0 & 212 & 200 \\
\hline $2^{*}$ & 0.0454 & 0.0392 & 28.7 & 20.3 & 0.9 & 2.5 & 0.8 & 1.2 & 230 & 269 \\
\hline 3 & 0.0796 & 0.0775 & 20.0 & 22.7 & 1.1 & 2.1 & 1.9 & 1.2 & 466 & 328 \\
\hline 4 & 0.0837 & 0.0848 & 25.2 & 27.4 & 2.2 & 4.4 & 2.9 & 2.3 & 418 & 333 \\
\hline 5 & 0.0980 & 0.0971 & 38.5 & 37.2 & 4.7 & 4.0 & 1.6 & nd & 153 & 124 \\
\hline Mean & & & 28.1 & 24.7 & 2.5 & 3.3 & 1.7 & 1.4 & 296 & 251 \\
\hline $\mathrm{SD}$ & & & 6.8 & 8.1 & 1.6 & 1.0 & 0.8 & 0.6 & 138 & 89 \\
\hline$p \dagger$ & & & NS & & 0.092 & & NS & & 0.104 & \\
\hline
\end{tabular}

* Subjects 1 and 2 received $250 \mathrm{mg}^{2} \mathrm{H}_{2} \mathrm{O} \mathrm{kg}$.

$\uparrow$ Probability, paired $t$ test; NS, not significant; nd, not done. 


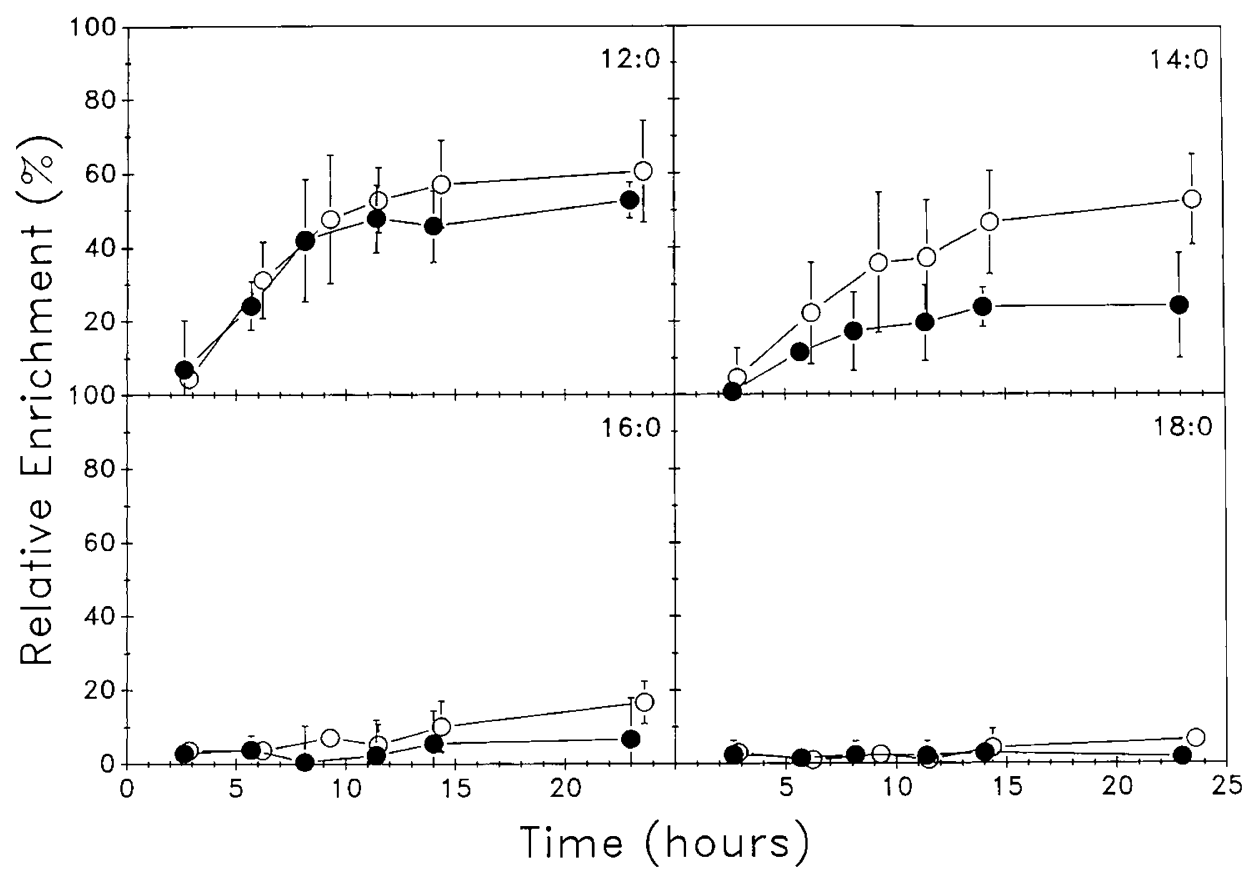

Fig. 4. The incorporation of deuterium from body water into specific milk FA in four women who received either a LF diet $(O)$ or a HF diet $(\bullet)$. These data are the relative enrichments (mean $\pm 1 \mathrm{SD}$ ) normalized to the body water deuterium enrichment.

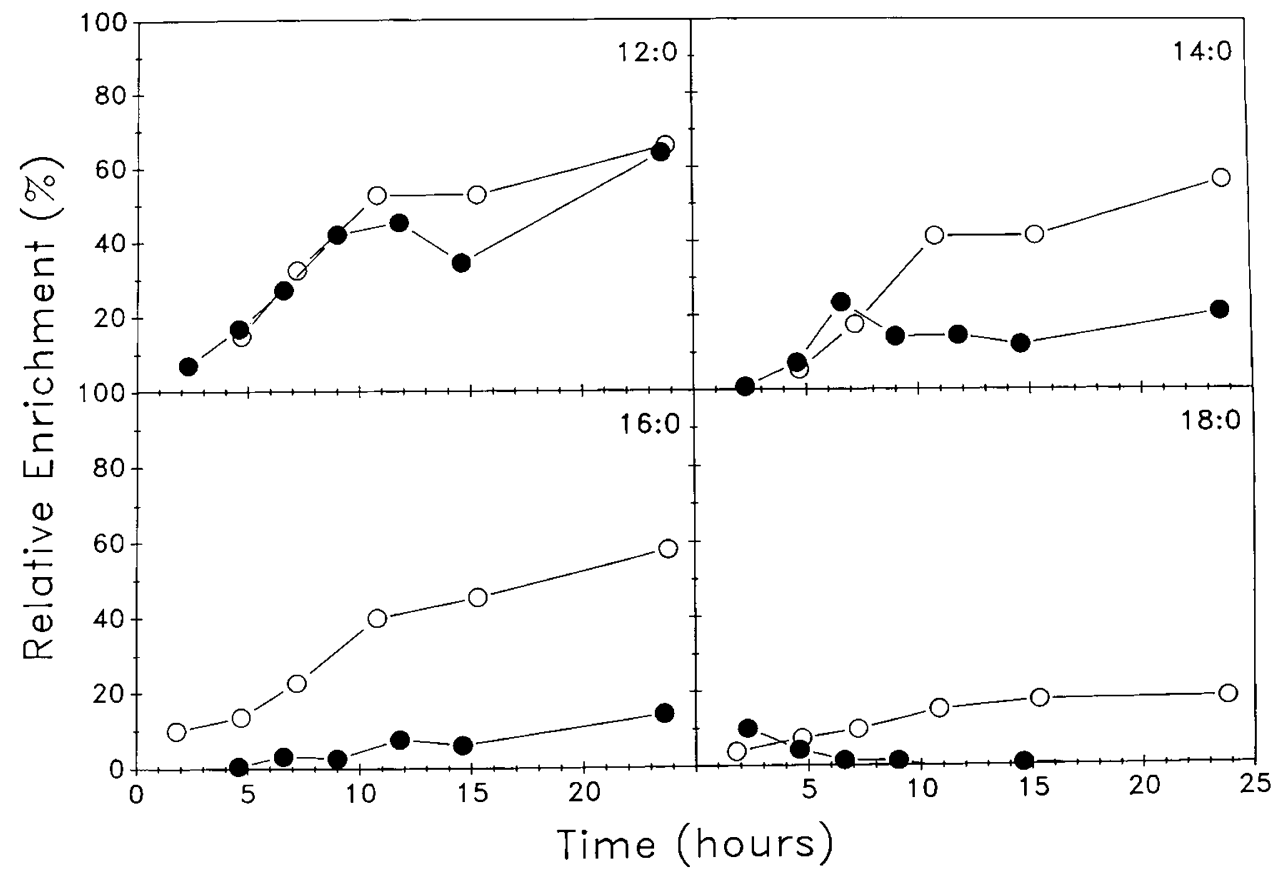

Fig. 5. Incorporation of deuterium from body water into specific milk FA in an individual (subject 3 ) who was able to synthesize C16:0 and C18:0. LF diet (O) and HF diet $(\bullet)$.

was synthesized by the breast. This value is the difference in isotopic enrichment between the two diets. If all of the C14:0 enrichment observed during the LF diet period were assumed to result from de novo synthesis by the breast, then any decrease in isotopic enrichment should reflect the entry of unlabeled dietary fat into milk. A similar response to dietary manipulation was observed in all five subjects. The human mammary gland is known to synthesize $\mathrm{C} 10: 0, \mathrm{C12}: 0$, and $\mathrm{C} 14: 0 \mathrm{FA}$, as demonstrated by Thompson and Smith (18) in mammary gland epithelial cell cultures.

The mammary gland apparently has a limited capacity to synthesize $\mathrm{C} 16: 0$ and $\mathrm{C} 18: 0$, even on the stringent LF diet. We observed a slight rise in the isotopic enrichment of milk $\mathrm{C} 16: 0$ in four of the women during the LF diet which we suspect was hepatic TG; however, no corresponding rise in C18:0 enrichment was observed. FA are synthesized by the FA synthetase complex. Chain elongation is stopped by a species-dependent enzyme, thioesterase II, which in the human mammary gland terminates the chain at C14:0 (19).

The studies we have described are unique in human lactation research. They illustrate the complex relationships between diet, energy metabolism, and milk composition. In most instances, alterations in maternal diet composition will have little effect on the lipid composition of the milk produced, provided that adipose stores are maintained. Only one subject was identified in whom the effects of altered nutrient intake had significant results. 


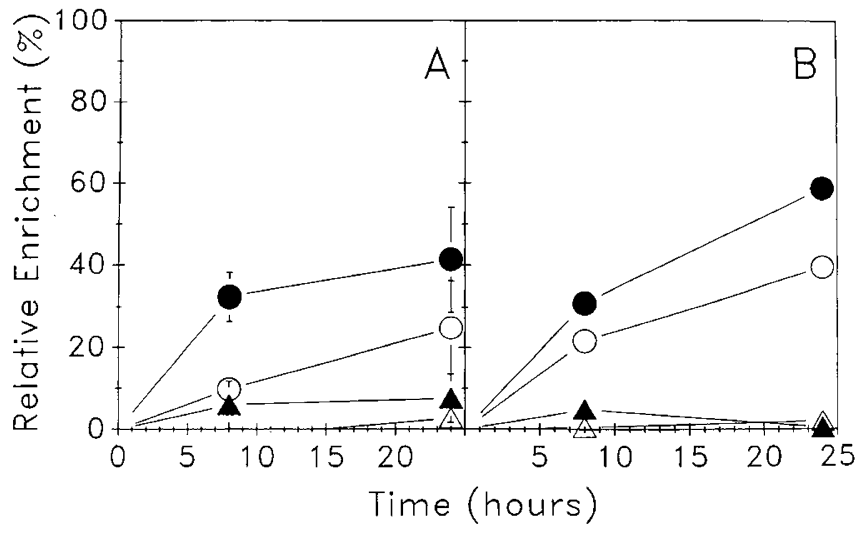

Fig. 6. Incorporation of deuterium from body water into plasma TG from normal women $(A)$ and from a woman (subject 3$)(B)$ who had the apparent ability to synthesize $\mathrm{C} 16: 0$ and $\mathrm{C} 18: 0$ in the mammary gland.

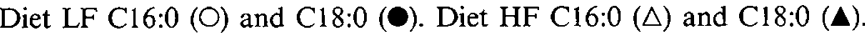
Deuterium enrichment.

The methods we have developed are safe and may have application to other areas of lipid metabolism.

Acknowledgments. We are indebted to M. Schanler for diet planning and for dietary analysis, to J. Hopkinson for assistance in recruiting subjects, to $\mathrm{E}$. O. Smith for assistance with statistical analysis of the data, to E. R. Klein and Y. C. Garza for editorial supervision of this manuscript, and to $\mathrm{M}$. E. Lewis for manuscript preparation. Special thanks are due to L. L. Clarke for deuterium isotope analysis in aqueous milk samples and to $\mathrm{L}$. Brown-Booth for isotopic analysis by GC-MS.

\section{REFERENCES}

1. Lammi-Keefe CJ, Jensen RG 1984 Lipids in human milk: a review. 2: Composition and fat soluble vitamins. J Pediatr Gastroenterol Nutr 3:172-

2. Bauman DE, Davis CL 1974 Biosynthesis of milk fat. In: Larson BL, Smith VR (eds) Lactation, A Comprehensive Treatise, volume 2. Academic Press, New York, pp 31-75
3. Vouri E, Kiuru K, Makinen SM, Vayrynen P, Kara R, Kuitunen P 1982 Maternal diet and fatty acid pattern of breast milk. Acta Paediatr Scand $71: 959-963$

4. Insull W, Hirsch J, James T, Ahrens EH 1959 The fatty acids of human milk: II: alterations produced by manipulation of caloric balance and exchange of dietary fats. J Clin Invest 38:443-450

5. Silber GH, Hachey DL, Schanler RJ, Garza C 1988 Manipulation of the maternal diet to alter the fatty acid composition of human milk intended for premature infants. Am J Clin Nutr 47:810-814

6. Read WWC, Lutz PG, Tashjian A 1965 Human milk lipids II: the influence of dietary carbohydrates and fat on the fatty acids of mature milk: a study of four ethnic groups. Am J Clin Nutr 17:180-183

7. Rittenberg D, Schoenheimer R 1937 Deuterium as an indicator in the study of intermediary metabolism: XI: further studies on the biological uptake of deuterium into organic substances, with special reference to fat and cholesterol formation. J Biol Chem 121:235-253

8. Wadke M, Brunengruber H, Lowenstein JM, Dolhun JJ, Arsenault GP 1973 Incorporation of deuterium and tritium into palmitic acid. Biochemistry 12:2619-2624

9. Schoeller DA, van Santen E, Peterson DW, Dietz W, Jaspan J, Klein PD 1980 Total body-water measurements in humans with $18 \mathrm{O}$ - and $2 \mathrm{H}$-labeled water. Am J Clin Nutr 33:2686-2693

10. Schonfeld G, Lees R, George PK, Pfleger B 1974 Assay of total plasma apolipoprotein $\mathrm{B}$ concentration in human subjects. $\mathrm{J}$ Clin Invest 53:14581467

11. Hachey DL, Thomas MR, Emken EA, Garza C, Brown-Booth L, Adlof RO Klein PD 1987 Human lactation: maternal transfer of dietary triglycerides labeled with stable isotopes. J Lipid Res 28:1185-1192

12. Wong WW, Lee LS, Klein PD 1987 Deuterium and oxygen-18 measurements on microliter samples of urine, plasma, saliva, and human milk. Am J Clin Nutr 45:905-913

13. Rozett RW 1974 Isotope abundances from mass spectra. Anal Chem $46: 2085-$ 2089

14. Klein PD, Boutton TW, Hachey DL, Irving CS, Wong WW 1986 The use of stable isotopes in metabolism studies. J Anim Sci 63:102-110

15. Berger GMB, Spark A, Baillie PM, Huskisson J, Stockwell G, Van DerMerwe E 1983 Absence of serum-stimulated lipase activity and altered lipid content in milk from a patient with type I hyperlipoproteinaemia. Pediatr Res $17: 835-839$

16. Knopp RH, Walden CE, Wahl PW, Bergelin R, Chapman M, Irvine S, Albers JJ 1985 Effect of postpartum lactation on lipoprotein lipids and apoproteins. J Clin Endocrin Metab 60:542-547

17. Weisweiler $P$, Janetschek $P$, Schwandt $P 1986$ Fat restriction alters the composition of apolipoprotein B-100 containing very low-density lipoproteins in humans. Am J Clin Nutr 43:903-909

18. Thompson BJ, Smith S 1985 Biosynthesis of fatty acids by lactating breast epithelial cells: an evaluation of the contribution to the overall composition of human fat. Pediatr Res 19:139-143

19. Dils R, Clark S, Knudsen J 1977 Comparative aspects of milk fat synthesis In: Peaker $M$ (ed) Comparative Aspects of Lactation. Academic Press, London, pp 43-55 